TITLE:

\title{
Leaf oil bodies are subcellular factories producing antifungal oxylipins.
}

AUTHOR(S):

Shimada, Takashi L; Hara-Nishimura, Ikuko

\section{CITATION:}

Shimada, Takashi L ... [et al]. Leaf oil bodies are subcellular factories producing antifungal oxylipins.. Current opinion in plant biology 2015, 25: 145-150

ISSUE DATE:

2015-06

URL:

http://hdl.handle.net/2433/201564

\section{RIGHT:}

(c) 2015. This manuscript version is made available under the CC-BY-NC-ND 4.0 license

http://creativecommons.org/licenses/by-nc-nd/4.0/; The full-text file will be made open to the public on 30 June 2017 in accordance with publisher's 'Terms and Conditions for Self-Archiving'.; This is not the published version. Please cite only the published version.; この論文は出版社版でありません。引用の際には出版社版をご確認じ利用ください。 


\title{
Leaf oil bodies are subcellular factories producing antifungal oxylipins
}

\section{Takashi L. Shimada ${ }^{1}$ and Ikuko Hara-Nishimura ${ }^{2}$}

\section{Addresses}

${ }^{1}$ Department of Biological Sciences, Graduate School of Science, University of Tokyo, Tokyo 113-0033, Japan

${ }^{2}$ Department of Botany, Graduate School of Science, Kyoto University, Kyoto 606-8502, Japan

Corresponding author: Ikuko Hara-Nishimura; Tel.: +81 (75) 753-4142; E-mail: ihnishi@gr.bot.kyoto-u.ac.jp

\begin{abstract}
Oil bodies act as lipid storage compartments in plant cells. In seeds they supply energy for germination and early seedling growth. Oil bodies are also present in the leaves of many vascular plants, but their function in leaves has been poorly understood. Recent studies with oil bodies from senescent $A$. thaliana leaves identified two enzymes, peroxygenase (CLO3) and $\alpha$-dioxygenase ( $\alpha$-DOX), which together catalyze a coupling reaction to produce an antifungal compound (2-hydroxy-octadecanoic acid) from $\alpha$-linolenic acid. Leaf oil bodies also have other enzymes including lipoxygenases, phospholipases, and triacylglycerol lipases. Hence, leaf oil bodies might function as intracellular factories to efficiently produce stable compounds via unstable intermediates by concentrating the enzymes and hydrophobic substrates.
\end{abstract}




\section{Oil bodies}

Lipids have an essential role for living organisms. In plants, lipids function as components of biomembranes (phospholipids and phytosterols), phytohormones (jasmonic acid), antifungal compounds (oxylipins), and storage lipids (triacylglycerols). Lipid metabolic pathways are localized in organelles such as endoplasmic reticulum (ER), plastids, peroxisomes, and mitochondria [1]. Some lipids are stored as lipid droplets in the cytosol or plastids. In this review, we define cytosolic lipid droplets as oil bodies, and plastidial lipid droplets as plastoglobules.

Oil bodies are surrounded by a phospholipid monolayer membrane with associated proteins, and contain neutral lipids inside [2]. Oil bodies are found in tissues such as seeds, tapetum in anthers, and leaves [3]. Seed oil-body membrane protein families include oleosins, caleosins, and steroleosins [4]. Oleosins are the major protein family in seed oil bodies, and function to inhibit oil-body fusion [5]. Oleosin action prevents formation of large oil bodies and preserves small oil body sizes. In Arabidopsis thaliana oleosin mutants, oil bodies are larger than those in wild type because the oil bodies easily fuse with each other [6,7]. The germination rate of oleosin mutant seeds is lower than that of wild-type seeds, and oleosin mutant seeds are susceptible to freezing [7]. These results suggest that oleosins have an important role in seed germination by preventing oil-body fusion. Some oleosin homologs are expressed in tapetum and are important for pollen formation [8-10].

Oleosin is abundant in seeds and tapetum, whereas oleosin levels are low in leaves [11], although leaf cells have oil bodies [12]. The functions of leaf oil bodies are unclear. However, recent research revealed the protein components of leaf oil bodies and their function. This review will explore leaf oil bodies.

\section{Leaf oil-body-localized proteins}

Leaf oil-body proteins have been identified as shown in Figure 1 and Table 1. Caleosins have the calcium-binding domain EF-hand and have a peroxygenase activity $[13,14]$. The CALEOSIN3/RESPONSIVE TO DESSICATION20/PEROXYGENASE3 (CLO3/RD20/PXG3) gene in A. thaliana is expressed in response to abiotic stresses [15]. The CLO3-GFP fusion protein localizes on leaf oil-body membranes [13], indicating that CLO3 is a leaf oil-body protein. CLO4 is expressed in leaves and the protein localizes on oil bodies [16], showing that CLO4 is a leaf oil-body protein. A. thaliana $\alpha$-dioxygenase1 ( $\alpha$-DOX1) was identified as a 
leaf oil-body protein by proteomics analysis of isolated leaf oil bodies [13]. Lipoxygenases [17], phospholipases [18,19], and triacylglycerol lipases [20] are oil-body proteins in seedlings. Lipoxygenases are involved in oil-body lipid metabolism. Phospholipases catalyze the conversion of oil-body membrane phospholipids to free fatty acids. Triacylglycerol lipases catalyze the conversion of oil-body storage lipids to free fatty acids. The A. thaliana triacylglycerol-lipase SUGAR-DEPENDENT1 (SDP1) localizes on oil bodies [21].

\section{Caleosins}

Caleosins are 20-30 kDa proteins containing a proline-knot motif, which is an oil-body binding domain, and an EF-hand motif, which is a calcium-binding domain [23]. The $A$. thaliana genome encodes at least eight caleosins. CLO1 (At4g26740) and CLO2 (At5g55240) are expressed in seed, whereas CLO3 (At2g33380) and CLO4 (At1g70670) are expressed in several tissues, including leaf [24]. According to the AtGenExpress database, CLO5 (At1g23240) is expressed in flower, CLO6 (At1g70680) is ubiquitously expressed in various organs, and CLO7 (At1g23250) is expressed in flower and seed, although CLO8 (At5g29560) has no expression data. CLO1, CLO2 and CLO3 have peroxygenase enzymatic activity $[13,14]$. CLO3 is expressed in response to the pathogenic fungus Colletotrichum higginsianum [13], abscisic acid, drought, and $\mathrm{NaCl}$ [15]. A study of seed-type caleosins reported that caleosins have peroxygenase activity, which catalyzes the oxidation of an unsaturated fatty acid by a hydroperoxy fatty acid to form a hydroxyl fatty acid and epoxy fatty acids [14]. This result suggests that caleosins function as enzymes involved in oxylipin metabolism.

Both CLO3 and $\alpha$-DOX1 are localized on leaf oil bodies during C. higginsianum infection [13]. CLO3 and $\alpha$-DOX1 cooperatively function to synthesize 2-hydroxy-octadecatrienoic acid (2-HOT) from $\alpha$-linolenic acid (Figure 2a) [13]. 2-HOT is an oxylipin with antifungal activity against Colletotrichum, and 2-HOT levels increase during senescence and $C$. higginsianum infection [13]. These results suggest that 2-HOT is an $A$. thaliana phytoalexin. Leaf oil bodies may function as a scaffold for the production of 2-HOT. In Nicotiana attenuata, 2-HOT is required for defense responses against larvae [25,26]. $2-\mathrm{HOT}$ has an additional function in inhibiting cell death [27,28]. Caleosins are conserved in several plants including angiosperms (SALAD Database [29], http://salad.dna.affrc.go.jp/salad/), Cycas revoluta [30], Physcomitrella patens [31], and 
Chlorella species [32]. These results suggest that land plants have an oil-body mediated defense mechanism that utilizes oxylipin production

Analysis of $\mathrm{CLO} 3$ mutant and overexpression lines indicates that CLO3 produces 13-hydroxyoctadecatrienoic acid (13-HOT) and 15,16-epoxy-13-HOT (Figure 2b) [33]. The 13-HOT oxylipin has antimicrobial activity against oomycete (Phytophthora parasitica) and fungi (Cladosporium herbarum, Botrytis cinerea) [34]. It is thought that 13-HOT is produced by caleosins from 13-hydroperoxyoctadecatrienoic acid (13-HPOT), which is produced by 13-lipoxygenase (13-LOX) using $\alpha$-linolenic acid (Figure 2b). A. thaliana has four 13-LOXs (LOX2, LOX3, LOX4 and LOX6) [35] that are expressed in rosette leaves (ATTED-II [22], http://atted.jp/). According to subcellular localization prediction by WoLF PSORT (http://www.genscript.com/psort/wolf_psort.html), LOX3 and LOX4 localize in cytosol. These cytosolic 13-LOXs might be associated with leaf oil bodies together with caleosins to produce the antimicrobial oxylipin 13-HOT.

\section{$\alpha$-Dioxygenase}

$\alpha$-Dioxygenase adds a hydroperoxy group to a branched chain of fatty acids and synthesizes 2-HPOT from $\alpha$-linolenic acid (Figure 2a) [36]. 2-HPOT is unstable and easily degrades to the aldehyde [36]. Because both CLO3 and $\alpha$-DOX1 are localized on leaf oil bodies, they efficiently synthesize 2-HOT utilizing the unstable intermediate 2-HPOT [13]. These results suggest that leaf oil bodies function as subcellular factories to efficiently produce the antifungal oxylipin 2-HOT.

A. thaliana has two $\alpha$-dioxygenase homologs, $\alpha$-DOX1 and $\alpha$-DOX2 [37,38]. $\alpha$-DOX1 is localized on leaf oil bodies, whereas $\alpha$-DOX2 is localized on ER [13]. The 2-HOT content in senescent and infected leaves of $\alpha$-doxl mutants is less than that of wild type, whereas the 2-HOT content of $\alpha$-dox2 mutants is similar to that of wild type [13]. These results suggest that only $\alpha$-DOX1 is necessary for 2 -HOT production in vivo. The fact that $\alpha$-dioxygenase is localized on oil bodies may be important for 2-HOT production. Defective $\alpha$-dioxygenase also reduces 2-HOT content in $N$. attenuata [25]. Silencing of $\alpha$-dioxygenase in $N$. attenuata produces plants that are smaller than wild type [25], whereas no phenotype was observed for $\alpha$-dox1 $\alpha$-dox2 double mutants of A. thaliana [39]. A. thaliana plants lacking $\alpha$-DOX1 enhances susceptibility to green peach aphid (Myzus persicae) [40]. These results suggest that $\alpha$-dioxygenase and 2-HOT have functional diversity among different plant species. The 
question regarding whether $\alpha$-dioxygenases in other plants are localized on leaf oil bodies should be the subject of future work. Infection of the pathogenic fungus Botrytis cinerea and treatment with elicitors of the pathogenic bacterium Pectobacterium carotovorum induce $\alpha$-DOX in P. patens [41], suggesting that $\alpha$-DOX-dependent defense mechanisms are conserved in land plants.

\section{Triacylglycerol lipase}

Fatty acids are the substrates of oxylipin production and energy sources. In oil bodies, fatty acids are bound with glycerol to produce triacylglycerol. Triacylglycerol lipases catalyze triacylglycerol metabolism to fatty acids. The triacylglycerol-lipase SDP1 [21], which is localized on oil bodies, is expressed in A. thaliana rosette leaves (ATTED-II [22], http://atted.jp/). Triacylglycerol contents in $s d p l$ leaves are slightly higher than those of the wild-type leaves, whereas triacylglycerol contents in $s d p 1$ roots are much higher than those of the wild-type roots [42]. SDP1 may function on leaf oil bodies.

\section{Leaf oil bodies in senescent leaves}

Senescent leaves contain more leaf oil bodies than young leaves (Figure 3) [43]. During senescence, CLO3 and $\alpha$-DOX1 expression and the amount of 2-HOT increase [13]. These results suggest that senescence is a key factor in leaf oil-body function. Old membranes and organelles are digested in senescent leaves, and some products of digestion can be translocated to new tissues. Peroxisomes in senescent leaves become specialized for fatty acid beta-oxidation and the glyoxylate cycle [44-46]. It is believed that lipids from old membranes and organelles are sequestered into leaf oil bodies, and then are metabolized by peroxisomes to provide an energy source.

Leaf oil bodies have an important role in defense mechanisms through oxylipin production, suggesting that senescent leaves containing abundant leaf oil bodies function as a defensive shield to inhibit pathogen invasion into new or healthy tissues [43]. Leaf oil bodies actively function in oxylipin production and defense response as well as lipid storage (Figure 3). This mechanism may protect the whole plant from pathogens [43].

\section{Sterol ester storage in leaf oil bodies}


Leaf oil bodies may have a role in storage of sterol esters. Over-production of sterols in plant cells enhances the formation of oil bodies [47]. Application of squalene, which is a sterol precursor, to the leaf surface elevates the sterol ester content and the number of leaf oil bodies [48]. By contrast, the amount of free sterols after squalene application is similar to that before application [48]. Phospholipid:sterol acyltransferase (PSAT) catalyzes the transfer of phospholipid fatty acyl groups to sterols [48]. Treatment of the A. thaliana psat1 mutant with squalene enhances leaf senescence but has no effect on the number of oil bodies [48]. These results suggest that excess sterols (which are toxic to plant cells) may be converted to sterol esters by PSAT and stored in leaf oil bodies (Figure 1). In the A. thaliana psat1 mutant, irregular cell death occurs in response to infection from the oomycete Phytophthora infestans [49]. Sterol storage in leaf oil bodies may have an important function in defense responses.

\section{Conclusion}

Plants produce bioactive lipids (oxylipins), usually in chloroplasts, to defend against pathogens and herbivores. A recent study provided evidence of bioactive compound production on leaf oil bodies of plants [13]. Plants have leaf oil body-mediated defense. Leaf oil bodies have an important role in plant defense by producing antimicrobial oxylipins $[13,33,34]$, one of which is the stable compound 2-HOT with antifungal activity against Colletotrichum, a fungus that causes significant damage to crops [43]. Senescent leaves contain a massive amount of leaf oil bodies. Leaf oil bodies produce 2-HOT in dying cells to accumulate high levels of the stable antifungal compound in dead cells, which could otherwise provide a source of fungal proliferation. Abscised leaves accumulating a large amount of antimicrobial compounds might prevent pathogenic fungi from replicating then spreading into healthy and young tissues. Considering the fact that leaf oil bodies and genes similar to $C L O 3$ and $\alpha-D O X 1$ are widely found in various land plants, plants might have evolved the leaf oil body-mediated phytoalexin production for defense against fungal proliferation.

\section{Acknowledgement}

This work was supported by Specially Promoted Research of Grant-in-Aid for Scientific Research to I.H-.N. (no. 22000014) from the Japan Society for the Promotion of Science (JSPS). 


\section{References and recommended reading}

Papers of particular interest, published within the period of review, have been highlighted as:

- of special interest

- of outstanding interest

1. Li-Beisson Y, Shorrosh B, Beisson F, Andersson MX, Arondel V, Bates PD, Baud S, Bird D, Debono A, Durrett TP, et al.: Acyl-lipid metabolism. Arabidopsis Book 2013, 11:e0161.

2. Shimada TL, Hara-Nishimura I: Oil-body-membrane proteins and their physiological functions in plants. Biol. Pharm. Bull. 2010, 33:360-363.

3. Murphy DJ: The dynamic roles of intracellular lipid droplets: from archaea to mammals. Protoplasma 2012, 249:541-585.

4. Jolivet P, Roux E, D'Andrea S, Davanture M, Negroni L, Zivy M, Chardot T: Protein composition of oil bodies in Arabidopsis thaliana ecotype WS. Plant Physiol. Biochem. 2004, 42:501-509.

5. Tzen JT, Huang AH: Surface structure and properties of plant seed oil bodies. J. Cell Biol. 1992, 117:327-335.

6. Siloto RM, Findlay K, Lopez-Villalobos A, Yeung EC, Nykiforuk CL, Moloney MM: The accumulation of oleosins determines the size of seed oilbodies in Arabidopsis. Plant Cell 2006, 18:1961-1974.

7. Shimada TL, Shimada T, Takahashi H, Fukao Y, Hara-Nishimura I: A novel role for oleosins in freezing tolerance of oilseeds in Arabidopsis thaliana. Plant J. 2008, 55:798-809.

8. Huang CY, Chen PY, Huang MD, Tsou CH, Jane WN, Huang AH: Tandem oleosin genes in a cluster acquired in Brassicaceae created tapetosomes and conferred additive benefit of pollen vigor. Proc. Natl. Acad. Sci. U. S. A. 2013, 110:14480-14485.

9. Suzuki T, Tsunekawa S, Koizuka C, Yamamoto K, Imamura J, Nakamura K, Ishiguro S: Development and disintegration of tapetum-specific lipid-accumulating organelles, elaioplasts and tapetosomes, in Arabidopsis thaliana and Brassica napus. Plant Sci. 2013, 207:25-36.

10. Jiang PL, Wang CS, Hsu CM, Jauh GY, Tzen JT: Stable oil bodies sheltered by a unique oleosin in lily pollen. Plant Cell Physiol 2007, 48:812-821.

11. Kim HU, Hsieh K, Ratnayake C, Huang AH: A novel group of oleosins is present inside the pollen of Arabidopsis. J. Biol. Chem. 2002, 277:22677-22684.

12. Lersten NR, Czlapinski AR, Curtis JD, Freckmann R, Horner HT: Oil bodies in leaf mesophyll cells of angiosperms: overview and a selected survey. Am. J. Bot. 2006, 93:1731-1739.

- 13. Shimada TL, Takano Y, Shimada T, Fujiwara M, Fukao Y, Mori M, Okazaki Y, Saito $\mathrm{K}$, Sasaki R, Aoki K, et al.: Leaf oil body functions as a subcellular factory for the production of a phytoalexin in Arabidopsis. Plant Physiol. 2014, 164:105-118.

This paper shows that AtCLO3 and At $\alpha$-DOX1 are localized on leaf oil bodies and cooperatively work for 2-HOT production. The authors found that 2-HOT is a phytoalexin 
against $C$. higginsianum and $C$. orbiculare.

- 14. Hanano A, Burcklen M, Flenet M, Ivancich A, Louwagie M, Garin J, Blee E: Plant seed peroxygenase is an original heme-oxygenase with an EF-hand calcium binding motif. J. Biol. Chem. 2006, 281:33140-33151.

This paper shows that caleosins of Arabidopsis thaliana has an enzymatic activity as peroxygenase.

15. Takahashi S, Katagiri T, Yamaguchi-Shinozaki K, Shinozaki K: An Arabidopsis gene encoding a Ca2+-binding protein is induced by abscisic acid during dehydration. Plant Cell Physiol. 2000, 41:898-903.

16. Kim YY, Jung KW, Yoo KS, Jeung JU, Shin JS: A stress-responsive caleosin-like protein, AtCLO4, acts as a negative regulator of ABA responses in Arabidopsis. Plant Cell Physiol. 2011, 52:874-884.

17. Feussner I, Hause B, Nellen A, Wasternack C, Kindl H: Lipid-body lipoxygenase is expressed in cotyledons during germination prior to other lipoxygenase forms. Planta 1996, 198:288-293.

18. May C, Preisig-Muller R, Hohne M, Gnau P, Kindl H: A phospholipase A2 is transiently synthesized during seed germination and localized to lipid bodies. Biochim. Biophys. Acta. 1998, 1393:267-276.

19. Rudolph M, Schlereth A, Korner M, Feussner K, Berndt E, Melzer M, Hornung E, Feussner I: The lipoxygenase-dependent oxygenation of lipid body membranes is promoted by a patatin-type phospholipase in cucumber cotyledons. J. Exp. Bot. 2011, 62:749-760.

20. Hills MJ, Murphy DJ: Characterization of lipases from the lipid bodies and microsomal membranes of erucic acid-free oilseed-rape (Brassica napus) cotyledons. Biochem. J. 1988, 249:687-693.

21. Eastmond PJ: SUGAR-DEPENDENT1 encodes a patatin domain triacylglycerol lipase that initiates storage oil breakdown in germinating Arabidopsis seeds. Plant Cell 2006, 18:665-675.

22. Obayashi T, Hayashi S, Saeki M, Ohta H, Kinoshita K: ATTED-II provides coexpressed gene networks for Arabidopsis. Nucleic Acids Res. 2009, 37:D987-991.

23. Chen JC, Tsai CC, Tzen JT: Cloning and secondary structure analysis of caleosin, a unique calcium-binding protein in oil bodies of plant seeds. Plant Cell Physiol. 1999, 40:1079-1086.

24. Shen Y, Xie J, Liu RD, Ni XF, Wang XH, Li ZX, Zhang M: Genomic analysis and expression investigation of caleosin gene family in Arabidopsis. Biochem. Biophys. Res. Commun. 2014, 448:365-371.

25. Steppuhn A, Gaquerel E, Baldwin IT: The two alpha-dox genes of Nicotiana attenuata: overlapping but distinct functions in development and stress responses. BMC Plant Biol. 2010, 10:171.

26. Gaquerel E, Steppuhn A, Baldwin IT: Nicotiana attenuata alpha-DIOXYGENASE1 through its production of 2-hydroxylinolenic acid is required for intact plant defense expression against attack from Manduca sexta larvae. New Phytol. 2012, 196:574-585.

27. Hamberg M, Sanz A, Rodriguez MJ, Calvo AP, Castresana C: Activation of the fatty 
acid alpha-dioxygenase pathway during bacterial infection of tobacco leaves. Formation of oxylipins protecting against cell death. J. Biol. Chem. 2003, 278:51796-51805.

28. Vicente J, Cascon T, Vicedo B, Garcia-Agustin P, Hamberg M, Castresana C: Role of 9-lipoxygenase and alpha-dioxygenase oxylipin pathways as modulators of local and systemic defense. Mol. Plant 2012, 5:914-928.

29. Mihara M, Itoh T, Izawa T: SALAD database: a motif-based database of protein annotations for plant comparative genomics. Nucleic Acids Res. 2010, 38:D835-842.

30. Jiang PL, Chen JC, Chiu ST, Tzen JT: Stable oil bodies sheltered by a unique caleosin in cycad megagametophytes. Plant Physiol. Biochem. 2009, 47:1009-1016.

31. Umate P: Comparative genomics of the lipid-body-membrane proteins oleosin, caleosin and steroleosin in magnoliophyte, lycophyte and bryophyte. Genomics Proteomics Bioinformatics 2012, 10:345-353.

32. Lin IP, Jiang PL, Chen CS, Tzen JT: A unique caleosin serving as the major integral protein in oil bodies isolated from Chlorella sp. cells cultured with limited nitrogen. Plant Physiol. Biochem. 2012, 61:80-87.

- 33. Blee E, Boachon B, Burcklen M, Le Guedard M, Hanano A, Heintz D, Ehlting J, Herrfurth C, Feussner I, Bessoule JJ: The Reductase Activity of the Arabidopsis Caleosin RESPONSIVE TO DESSICATION20 Mediates Gibberellin-Dependent Flowering Time, Abscisic Acid Sensitivity, and Tolerance to Oxidative Stress. Plant Physiol. 2014, 166:109-124.

The authors show that AtCLO3 is related to 13-HOT production, flowering, abscisic acid sensitivity, and stress tolerance.

- 34. Prost I, Dhondt S, Rothe G, Vicente J, Rodriguez MJ, Kift N, Carbonne F, Griffiths G, Esquerre-Tugaye MT, Rosahl S, et al.: Evaluation of the antimicrobial activities of plant oxylipins supports their involvement in defense against pathogens. Plant Physiol. 2005, 139:1902-1913.

The authors show antimicrobal activities of oxylipins such as 2-HOT and 13-HOT.

35. Bannenberg G, Martinez M, Hamberg M, Castresana C: Diversity of the enzymatic activity in the lipoxygenase gene family of Arabidopsis thaliana. Lipids 2009, 44:85-95.

- 36. Hamberg M, Sanz A, Castresana C: alpha-oxidation of fatty acids in higher plants. Identification of a pathogen-inducible oxygenase (piox) as an alpha-dioxygenase and biosynthesis of 2-hydroperoxylinolenic acid. J. Biol. Chem. 1999, 274:24503-24513.

The authors investigate the enzymatic activity of $\alpha$-dioxygenase.

37. Hamberg M, Ponce de Leon I, Rodriguez MJ, Castresana C: Alpha-dioxygenases. Biochem. Biophys. Res. Commun. 2005, 338:169-174.

38. Tirajoh A, Aung TS, McKay AB, Plant AL: Stress-responsive alpha-dioxygenase expression in tomato roots. J. Exp. Bot. 2005, 56:713-723.

39. Bannenberg G, Martinez M, Rodriguez MJ, Lopez MA, Ponce de Leon I, Hamberg M, Castresana $C$ : Functional analysis of alpha-DOX2, an active alpha-dioxygenase critical for normal development in tomato plants. Plant Physiol. 2009, 151:1421-1432. 
40. Avila CA, Arevalo-Soliz LM, Lorence A, Goggin FL: Expression of alpha-DIOXYGENASE 1 in tomato and Arabidopsis contributes to plant defenses against aphids. Mol. Plant Microbe. Interact. 2013, 26:977-986.

41. Machado L, Castro A, Hamberg M, Bannenberg G, Gaggero C, Castresana C, de Leon IP: The Physcomitrella patens unique alpha-dioxygenase participates in both developmental processes and defense responses. BMC Plant Biol. 2015, 15:45.

42. Kelly AA, van Erp H, Quettier AL, Shaw E, Menard G, Kurup S, Eastmond PJ: The sugar-dependent1 lipase limits triacylglycerol accumulation in vegetative tissues of Arabidopsis. Plant Physiol. 2013, 162:1282-1289.

43. Shimada TL, Takano Y, Hara-Nishimura I: Oil body-mediated defense against fungi: From tissues to ecology. Plant Signal. Behav. 2015, 10:e989036.

44. Hayashi M, Toriyama K, Kondo M, Kato A, Mano S, De Bellis L, Hayashi-Ishimaru Y, Yamaguchi K, Hayashi H, Nishimura M: Functional transformation of plant peroxisomes. Cell Biochem. Biophys. 2000, 32 Spring:295-304.

45. Nishimura M, Hayashi M, Kato A, Yamaguchi K, Mano S: Functional transformation of microbodies in higher plant cells. Cell Struct. Funct. 1996, 21:387-393.

46. Pracharoenwattana I, Smith SM: When is a peroxisome not a peroxisome? Trends Plant Sci. 2008, 13:522-525.

47. Schaller H, Grausem B, Benveniste P, Chye ML, Tan CT, Song YH, Chua NH:

Expression of the Hevea brasiliensis (H.B.K.) Mull. Arg.

3-Hydroxy-3-Methylglutaryl-Coenzyme A Reductase 1 in Tobacco Results in Sterol Overproduction. Plant Physiol. 1995, 109:761-770.

- 48. Bouvier-Nave P, Berna A, Noiriel A, Compagnon V, Carlsson AS, Banas A, Stymne S, Schaller H: Involvement of the phospholipid sterol acyltransferase1 in plant sterol homeostasis and leaf senescence. Plant Physiol. 2010, 152:107-119.

This paper shows that phospholipid sterol acyltransferase1 works for sterol ester biosinthesis and that leaf oil bodies are formed by sterol application.

49. Kopischke M, Westphal L, Schneeberger K, Clark R, Ossowski S, Wewer V, Fuchs R, Landtag J, Hause G, Dormann P, et al.: Impaired sterol ester synthesis alters the response of Arabidopsis thaliana to Phytophthora infestans. Plant J. 2013, 73:456-468. 


\section{Figure Legends}

Figure 1. A schematic view of a leaf oil body and associated proteins. Enzyme families localized on leaf oil bodies and their substrates and products. PSAT, phospholipid:sterol acyltransferase; 2-HOT, 2-hydroxy-octadecatrienoic acid; 13-HOT, 13-hydroxy-octadecatrienoic acid.

Figure 2. Lipid metabolic pathways of leaf oil bodies. (a) Two leaf oil-body proteins, caleosin and $\alpha$-dioxygenase, cooperatively produce 2 -HOT from $\alpha$-linolenic acid. 2-HPOT, 2-hydroperoxy-octadecatrienoic acid. Fatty acid epoxides are possible products. (b) A biosynthetic pathway to produce 13-HOT from $\alpha$-linolenic acid.

Figure 3. Induction of leaf oil bodies during senescence. Leaf oil bodies are few in green leaves and then are induced in senescent leaves. Leaf oil bodies actively function in oxylipin biosynthesis and defense response, although seed oil bodies function in lipid storage. 


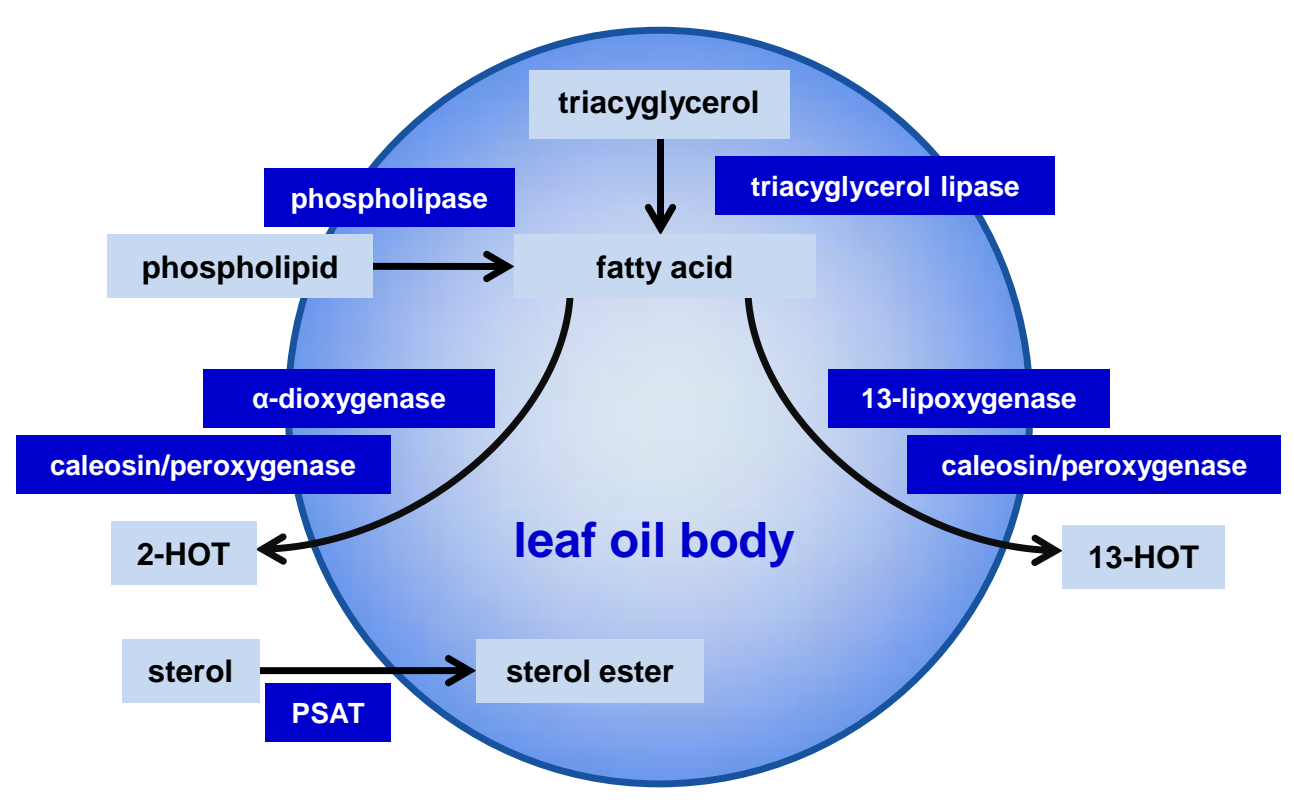


(a)
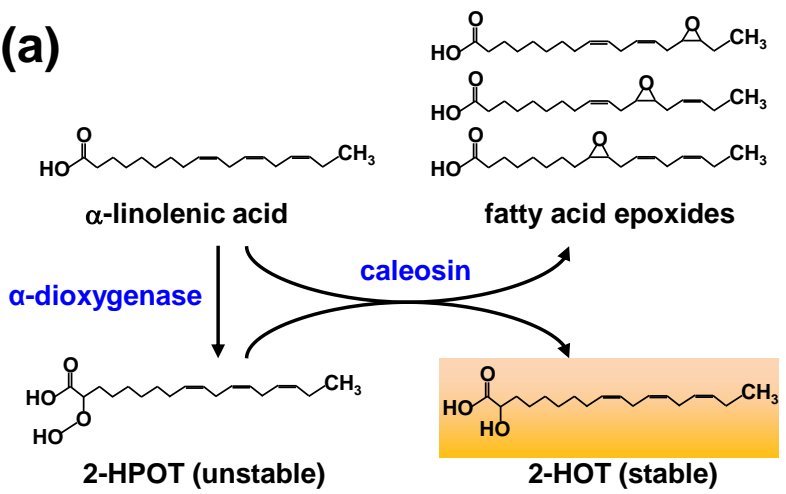

(b)

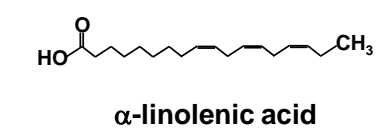

13-lipoxygenase

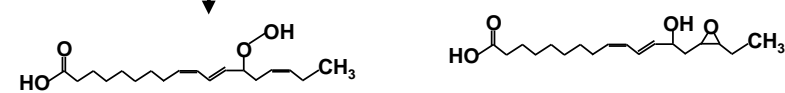
13-HPOT

15,16-ероху-13-HOT
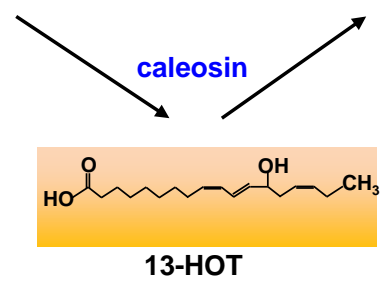

Figure 2 


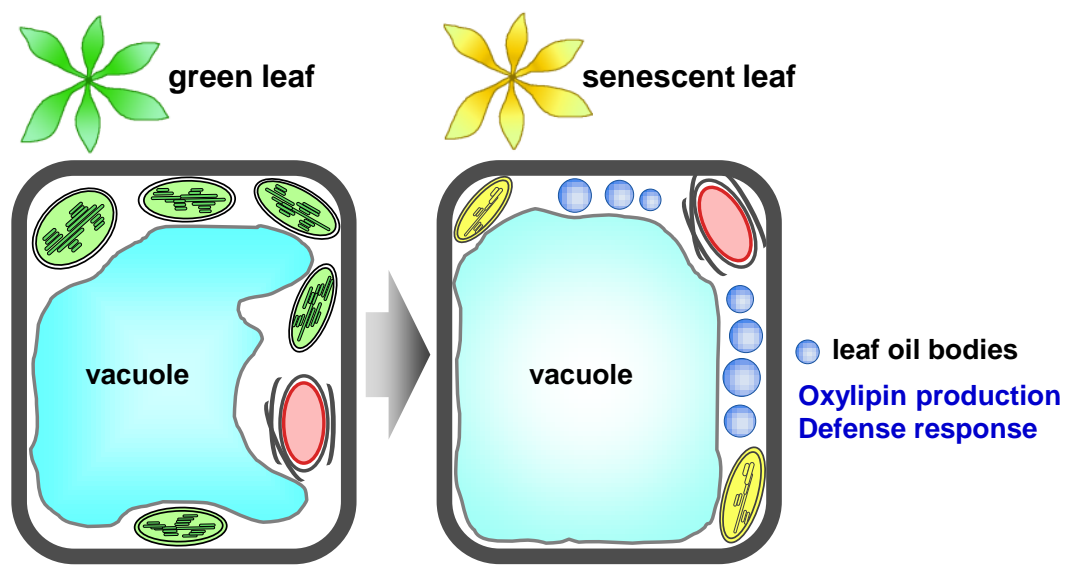


Table1 | Leaf oil-body proteins

\begin{tabular}{lllll}
\hline Protein & Enzymatic activity & Species & Accession & Reference \\
\hline CLO3/RD20/PXG3 & peroxygenase & Arabidopsis thaliana & At2g33380 & {$[13,15,24,33]$} \\
CLO4 & peroxygenase ${ }^{2}$ & Arabidopsis thaliana & At1g70670 & {$[16,24]$} \\
CLO6 & peroxygenase ${ }^{2}$ & Arabidopsis thaliana & At1g70680 & {$[24]$} \\
a-DOX1 & a-dioxyganase & Arabidopsis thaliana & At3g01420 & {$[13,36,37,38]$} \\
SDP1 & triacylglycerol-lipase & Arabidopsis thaliana & At5g04040 & {$[21,42]$} \\
patatin-like protein ${ }^{1}$ & phospholipase A $A_{2}$ & Cucumis sativus & Y12793 & {$[18,19]$} \\
\hline
\end{tabular}

${ }^{1}$ induced in seedling, ${ }^{2}$ possible roles 